\title{
Antischistosomal activity of artemether in experimental Schistosomiasis mansoni
}

Susana Zevallos Lescano ${ }^{a}$, Pedro Paulo Chieffia,b, Rosa Regina Canhassia ${ }^{a}$, Marcos Boulos ${ }^{c}$ and Vicente Amato Neto ${ }^{d}$

aLaboratório de Imunopatologia da Esquistossomose (LIM 06) do Instituto de Medicina Tropical de São Paulo. São Paulo, SP, Brasil. baculdade de Ciências Médicas da Santa Casa de São Paulo. São Paulo, SP, Brasil. ' Departamento de Doenças Infecciosas e Parasitárias da Faculdade de Medicina da Universidade de São Paulo. São Paulo, SP, Brasil. dLaboratório de Parasitologia (LIM 46) do Instituto de Medicina Tropical de São Paulo. São Paulo, SP, Brasil

\section{ABSTRACT}

\section{Objective}

To evaluate the effect of intramuscular injection of artemether in mice experimentally infected with Schistosoma mansoni, at the time of infection, during schistosomula maturation and after the beginning of egg-laying.

\section{Methods}

Eighty adult females Balb/c mice were divided into 8 groups with 10 animals each. Seven groups were infected with S. mansoni using 60 cercariae for each animal, inoculated subcutaneously, and the remaining group was maintained without infection. Among the seven infected groups, six were treated 
with artemether, according to the following schedule: three groups received doses of $100 \mathrm{mg} / \mathrm{kg}$ on days 0,20 or 60 after inoculation of the cercariae; the other three received $50 \mathrm{mg} / \mathrm{kg}$ of artemether, also on days 0,20 or 60 . At the end of the $9^{\text {th }}, 10^{\text {th }}$ and $11^{\text {th }}$ weeks after infection all the mice infected with S. mansoni were submitted to fecal examination using the Kato-Katz technique. On the $80^{\text {th }}$ day of the experiment, the surviving animals were sacrificed and submitted to perfusion of the portal system in order to recover the worms. Body, liver and spleen weights of each animal were determined at that time.

\section{Results}

A reduction in egg-laying and the number of worms recovered was observed in mice treated with artemether $\left(50\right.$ or $100 \mathrm{mg} / \mathrm{kg}$ ) on the $20^{\text {th }}$ day after infection. The decrease in the number of worms was more notable among $\mathrm{S}$. mansoni females. A significant decrease in liver and spleen weights was also seen on the $20^{\text {th }}$ day among animals treated with 50 or $100 \mathrm{mg} / \mathrm{kg}$ of artemether and also among those that received the drug at a dose of $50 \mathrm{mg} / \mathrm{kg} 60$ days after infection.

\section{Conclusions}

Evidence of the antischistosomal activity of artemether was shown, even at a dose of $50 \mathrm{mg} / \mathrm{kg}$, when the drug was administered during the schistosomula maturation period in the portal system of the vertebrate host.

\section{Keywords}

Schistosoma mansoni. Artemisinins, therapeutic use. Schistosomiasis mansoni, drug therapy. Animal experimentation. Artemether.

\section{NTRODUCTI ON}

It is believed that at least 2.5 million people in Brazil carry Schistosoma mansoni and around 25 million individuals are exposed to the risk of contracting it. ${ }^{9}$

Two drugs have been widely used in the treatment of the disease, with good efficacy and low toxicity: oxamniquine and praziquantel. Over recent years, the latter has been used preferentially. In view of the possible development of tolerance or resistance to praziquantel, research into and production of new drugs for the prevention and cure of Schistosoma mansoni has become justified. ${ }^{4}$

Artemisinin derivatives, which are used with efficacy in the treatment of malaria, have also been shown to have anti-Schistosoma activity, especially artemether. The schistosomicide action of artemisinin was discovered in 1980 by Chinese scientists. In their study, when it was administered to animals infected experimentally with Schistosoma japonicum, it caused a marked reduction in worm load in comparison with control animals that were not treated (Chen et al apud Utzinger et al, ${ }^{11}$ 2001). 
In 1982, Le et $\mathrm{al}^{7}$ confirmed the schistosomicide property of artemether. Mice or dogs infected with S. japonicum and treated with this drug at various doses and utilizing different administration routes showed a significant reduction in worm load. The larval phases (schistosomulae) of S. japonicum were also shown to be susceptible to artemether. However, no effect was observed on trematode eggs. ${ }^{15}$ Subsequent studies have confirmed that other artemisinin derivatives have schistosomicide properties: artesunate, ${ }^{3,8}$ arteether $^{14}$ and, recently, dihydroartemisinin. ${ }^{1}$ In 1991 in Brazil, Araújo et $\mathrm{al}^{2}$ studied artemether activity in hamsters and mice experimentally infected with $\mathrm{S}$. mansoni, 45 days after penetration by the cercariae. Better results were also observed when the drug was administered via intramuscular route.

The present work has sought to evaluate the effect of the intramuscular administration of artemether in mice experimentally infected with S. mansoni, at the time of infection, during schistosomula maturation and after the beginning of egg- laying.

\section{METHODS}

Eighty adult female mice of the Balb/c lineage were utilized, divided into eight subgroups: six infected with S. mansoni and treated using artemether, one equally infected but not treated with artemether and, finally, one other subgroup that was not infected and not treated, as shown in Table 1.

Table 1 - Artemether treatment schedule, via intramuscular route, for the mice infected with S. mansoni.

\begin{tabular}{llll}
\hline Subgroup & No. of mice & Dose & Day of treatment \\
\hline 1 & 10 & $100 \mathrm{mg} / \mathrm{kg}$ of weight & zero \\
2 & 10 & $100 \mathrm{mg} / \mathrm{kg}$ of weight & 20 a.i. \\
3 & 10 & $100 \mathrm{mg} / \mathrm{kg}$ of weight & 60 a.i. \\
4 & 10 & $50 \mathrm{mg} / \mathrm{kg}$ of weight & zero \\
5 & 10 & $50 \mathrm{mg} / \mathrm{kg}$ of weight & 20 a.i. \\
6 & 10 & $50 \mathrm{mg} / \mathrm{kg}$ of weight & 60 a.i. \\
7 & 10 & Infected control & Not treated \\
8 & 10 & Free of infection & Not treated \\
\hline
\end{tabular}

a.i. = after infection

The mice in subgroups 1 to 7 were each infected with 60 cercariae of the BH strain of S. mansoni, via subcutaneous route. The BH strain of this trematode has been kept for more than 15 years in the schistosomiasis immunopathology laboratory of Instituto de Medicina Tropical de São Paulo (São Paulo Institute of Tropical Medicine), by utilizing specimens of Biomphalaria glabrata and hamsters. The inoculation of 60 cercariae was achieved by 1:6 dilution of an aliquot that contained 1800 cercariae per $\mathrm{ml}$, with $0.2 \mathrm{ml}$ injected into each mouse. The artemether, at doses of 50 and $100 \mathrm{mg} / \mathrm{kg}$, was administered via intramuscular route to the mice in subgroups 1 to 6 .

The effect of the artemether was evaluated by me ans of quantitative examination of feces, done according to the Kato-Katz method ${ }^{6}$ in the $9^{\text {th }}, 10^{\text {th }}$ and $11^{\text {th }}$ weeks after the infection. Eighty days after the start of the experiment, the surviving animals were sacrificed and submitted to perfusion of the portal system for the recovery and counting of the worms present, according to the technique recommended by Pellegrino \& Siqueira. ${ }^{10}$ At that time, the body, liver, and spleen weights of each mouse were determined. 
Throughout the experiment the mice received feed and water ad libitum and their management was in accordance with the recommendations of the Colégio Brasileiro de Experimentação Animal (Brazilian College for Animal Experimentation).

The results were analyzed via non-parametric statistical tests, utilizing a significance level of $95 \%$ $(p=0.05)$.

\section{RESULTS}

Table 2 shows the average number of S. mansoni eggs per gram of feces obtained from the different mouse subgroups in the $9^{\mathrm{h}}, 10^{\text {th }}$ and $11^{\text {th }}$ weeks after infection. In subgroups 2 and 5 , treated with artemether on the $20^{\text {th }}$ day after infection with doses of $100 \mathrm{mg} / \mathrm{kg}$ and $50 \mathrm{mg} / \mathrm{kg}$, respectively, there was a marked reduction in the number of eggs found.

Table 2 - Results from the feces examinations (Kato Katz) between the $9^{\text {th }}$ and $11^{\text {th }}$ weeks after infection with $S$. mansoni, in the mice treated with artemether and untreated mice.

\begin{tabular}{|c|c|c|c|c|}
\hline $\begin{array}{l}\text { Subgroup } \\
\text { (artemether dose) }\end{array}$ & No. of mice examined & $\begin{array}{l}\text { Eggs per gra } \\
9^{\text {th }} \text { week a.i. }\end{array}$ & $\begin{array}{l}\mathrm{m} \text { of feces } \\
10^{\text {th }} \text { week a.i. }\end{array}$ & $11^{\text {th }}$ week a.i. \\
\hline 1 (100 mg/kg, day 0) & 10 & 239.0 & 168 & 158.4 \\
\hline $2(100 \mathrm{mg} / \mathrm{kg}, 20$ days a.i.) & 10 & 19.2 & 0 & 0 \\
\hline $\begin{array}{ll}3 & (100 \mathrm{mg} / \mathrm{kg}, 60 \text { days a.i.) } \\
4 & (50 \mathrm{mg} / \mathrm{kg} \text {, day 0) }\end{array}$ & $\begin{array}{l}6 \\
9\end{array}$ & 75.4 & $\begin{array}{l}85.7 \\
125.3\end{array}$ & $\begin{array}{l}0 \\
1120\end{array}$ \\
\hline 5 (50 mg/kg, 20 days a.i.) & 10 & 0 & 12.0 & 4.8 \\
\hline 6 (50 mg/kg, 60 days a.i.) & 10 & 103.2 & 138.0 & 7.2 \\
\hline 7 (Untreated) & 8 & 269.3 & 243.0 & 147.0 \\
\hline
\end{tabular}

a.i. $=$ after infection

Table 3 presents the data relating to the number of worms recovered after perfusion of the portal system of the surviving animals.

Table 3 - Average number of worms recovered from the mice infected with $\mathbf{S}$. mansoni and treated with different doses of artemether.

\begin{tabular}{lllll}
\hline Subgroup & No. of mice perfused & Females & Males & Worms \\
\hline & & $\mathbf{N}$ & $\mathrm{N}$ & $\mathrm{N}$ \\
1 & 10 & $3.0 \pm 3.85$ & $9.0 \pm 4.07$ & $12.0 \pm 6.97$ \\
2 & 10 & $0.1 \pm 0.31^{*}$ & $1.3 \pm 1.83^{*}$ & $1.4 \pm 1.9^{*}$ \\
3 & 6 & 0.0 & $8.5 \pm 6.53$ & $8.5 \pm 6.53$ \\
4 & 9 & $0.75 \pm 0.88$ & $6.87 \pm 9.34$ & $7.62 \pm 9.78$ \\
5 & 10 & $0.2 \pm 0.42^{*}$ & $2.8 \pm 6.83$ & $3.0 \pm 6.81$ \\
6 & 10 & $0.125 \pm 0.35^{*}$ & $1.75 \pm 2.71^{*}$ & $1.85 \pm 2.95^{\star}$ \\
7 & 8 & $1.67 \pm 2.34$ & $6.0 \pm 8.03$ & $7.67 \pm 10.16$ \\
\hline
\end{tabular}

* Significant difference. 
The ratios between the liver and spleen weights and body weights of the mice in the different groups studied are presented in Table 4. A significant difference was observed between the values found for animals in subgroups 2, 5 and 6 and those of the mouse subgroup that was infected but not treated with artemether (subgroup 7).

Table 4 - Ratios of spleen weight $X 100$ / body weight and liver weight $X 100$ / body weight in mice infected with $S$. mansoni and treated with artemether.

\begin{tabular}{llll}
\hline Subgroup & No. of mice examined & Spleen weight $\times 100 /$ body weight & Liver weight $\times 100 /$ body weight \\
\hline 1 & 10 & $1.137 \pm 0.44$ & $6.817 \pm 1.68$ \\
2 & 10 & $0.675 \pm 0.09^{*}$ & $5.536 \pm 0.70^{*}$ \\
3 & 6 & $1.078 \pm 0.24$ & $6.732 \pm 0.56$ \\
4 & 9 & $1.262 \pm 0.80$ & $7.426 \pm 2.31$ \\
5 & 10 & $0.704 \pm 0.22^{*}$ & $4.617 \pm 1.02^{*}$ \\
6 & 10 & $0.705 \pm 0.18^{*}$ & $5.631 \pm 1.12^{*}$ \\
7 & 8 & $1.46 \pm 0.60$ & $8.021 \pm 1.85$ \\
8 & 10 & $0.402 \pm 0.09$ & $4.443 \pm 0.80$ \\
\hline
\end{tabular}

* Significant difference

\section{DISCUSSION}

Schistosomiasis continues to occupy second position in the world among parasites, after malaria, in terms of the extent of endemic areas and number of people infected. Treatment using praziquantel is efficacious in the reduction of morbidity, although it fails to prevent reinfection. Thus, foci with high transmission rates still exist in endemic areas, despite the regular administration of this drug. ${ }^{13}$ In view of the possible development of tolerance and/or resistance to this drug, research into new alternatives for the prevention and cure of schistosomiasis have become justified. ${ }^{4}$

Artemisinin (qinghaosu) is the main active agent extracted from the leaves of Artemisia annua, a plant that is widely disseminated in China and which also grows naturally in Central Europe, the United States and Argentina. Its antimalarial activity was confirmed in 1971 and more than two million patients with malaria have been treated with this drug and its derivatives (artemether, artesunate and arteether) over that last 20 years. ${ }^{11}$ The antischistosomal activity of artemisinin was discovered in 1980, when it was observed that its administration to animals experimentally infected with S. japonicum caused a marked reduction in the worm load, in comparison with control animals that were not treated. ${ }^{11}$ These results were confirmed by the findings of Le et al ${ }^{7}$ (1982). In their turn, Yue et $\mathrm{al}^{15}$ (1984) verified the susceptibility of the schistosomulae of S. japonicum to artemether. They did not, however, observe any effect of this drug on the eggs of this trematode.

An experimental study made by Chinese researchers showed that artemether had greater activity against S. mansoni when the drug, used at a high dose $(400 \mathrm{mg} / \mathrm{kg})$, was utilized during the phase of schistosomula evolution (14 to 21 days after penetration by the cercariae), with lesser activity shown in relation to adult worms. A study done in Brazil (Araújo et $\mathrm{al}^{2}{ }^{2} 1991$ ) confirmed the moderate reduction in parasite load when artemether was used in mice carrying adult specimens of $\mathrm{S}$. mansoni.

The present work sought to utilize lower doses of artemether, closer to those utilized in human beings in the treatment of malaria, with the objective of simulating situations that could arise in regions where malaria and schistosomiasis are endemic. The results obtained similarly suggested that there is greater activity of artemether on schistosomulae (Table 3). In the animals in subgroups 2 and 5 (infected and treated with $100 \mathrm{mg}$ and $50 \mathrm{mg}$ of artemether per $\mathrm{kg}$ of weight, on the $20^{\text {th }}$ day after infection, at which time the maturation of the schistosomulae was taking place), fewer worms were 
recovered after the perfusion of the portal system. These results were confirmed by the absence or low counts of eggs in the feces of mice in these subgroups in the $10^{\text {th }}$ and $11^{\text {th }}$ weeks after infection (Table 2). These finding partially coincide with those of Xiao \& Catto ${ }^{12}$ (1989) and Xiao et $\mathrm{al}^{13}(2000)$, who worked with mice infected with S. mansoni and observed that the parasites aged 14 and 21 days were the ones most susceptible to artemether. It should be stressed that lower mortality was observed in the subgroups treated with artemether (with the exception of subgroup 3, which received the drug when the S. mansoni specimens were already fully developed), than in subgroup 7 (mice infected with S. mansoni and not treated with artemether).

The animals in subgroups 3 and 6 - treated 60 days after infection, with $100 \mathrm{mg}$ and $50 \mathrm{mg}$ of artemether per $\mathrm{kg}$ of weight - presented lower numbers of female worms after the perfusion (Table 3 ) and the egg count was negative in the last week of the experiment (Table 2). Evidence was thus shown of the antiparasitic activity of artemether, especially in relation to schistosomulae and females of S. mansoni, even when lower doses of this drug were utilized.

In Brazil, there is practically no overlap between the endemic areas for malaria and schistosomiasis. However, in certain regions of the African continent, the transmission of these parasitoses takes place concomitantly, and the results from the use of praziquantel have been less promising than what was expected $^{5}$. In these circumstances, the use of artemisinin derivatives with the aim of treating malaria cases may exert a significant influence on the reduction of the morbidity rate due to endemic schistosomiasis.

\section{REFERENCES}

1. Abdel-Aziz SS, El-Badawy NM. Experimental trials of an artemisinin derivative in treatment of Schistosoma mansoni infected mice. J Egypt Soc Parasitol 2000;30:295-303.

2. Araujo N, Kohn A, Katz N. Activity of the Artemether in experimental Schistosomiasis mansoni. Mem Inst Oswaldo Cruz 1991; 86 ( Suppl 2): 185-8.

3. Araujo N, Kohn A, Katz N. Avaliação terapêutica do artesunato na infecção experimental pelo Schistosoma mansoni. Rev Soc Brasil Med Trop 1999; 32: 7- 12.

4. Cioli D. Praziquantel: is there real resistence and are there alternatives? Curr Opin Infect Dis 2000; 13:659- 63.

5. Danso-Appiah A, De Vlas SJ. Interpreting low praziquantel cure rates of Schistosoma mansoni infections in Senegal. Trends Parasit 2002;18:125-9.

6. Katz N, Chaves A, Pellegrino J. A simple device for quantitative stool thick smear technique in schistosomiasis mansoni. Rev Inst Med Trop S Paulo 1972; 14: 397- 400.

7. Le W, You J, Yang Y. Studies on the efficacy of artemether in experimental schistosomiasis. Acta Pharm Sin 1982; 17: 187-93. 
8. Le W, You J, Mei J. Chemotherapeutic effect of artesunate in experimental schistosomiasis. Acta Pharm Sin 1983; 18:619-21.

9. Passos ADC, Amaral RS. Esquistossomose mansônica: aspectos epidemiológicos e de controle. Rev Soc Bras Med Trop 1998; 31(Supl 2): 61- 74.

10. Pellegrino J, Siqueira AF. Técnica de perfusão para colheita de Schistosoma mansoni em cobaias experimentalmente infectadas. Rev Bras Malariol 1956; 8:589- 97.

11. Utzinger J, Xiao SH, N'goran EK, Bergquist R, Tanner M. The potential of artemether for the control of schistosomiasis. Int J Parasit 2001;31:1549-62.

12. Xiao SH, Catto BA. In vitro and in vivo studies of the effect of Artemether on Schistosoma mansoni. Antimicrob Agents Chemother 1989;33:1557- 62.

13. Xiao SH, Chollet J, Weiss NA, Bergquist RN, Tanner M. Preventive effect of artemether in experimental animals infected with Schistosoma mansoni. Parasitol Int 2000; 49: 19- 24.

14. Yin JW, Yang YQ, Xiao SH, Li Y, Jiang HJ. Comparative studies on histological and histochemical alterations of Schistosoma japonicum induced by arteether and artemether. Acta Pharmacol Sin $1991 ; 12: 478-80$.

15. Yue WJ, You JQ, Mei JY. Effects of artemether on Schistosoma japonicum adult worms and ova. Acta Pharmacol Sin 1984;5:60-3.

\section{Address to correspondence}

Pedro Paulo Chieffi

Instituto de Medicina Tropical

Av. Dr. Enéas Carvalho de Aguiar, $5002^{\circ}$ andar Cerqueira César

05403-000 São Paulo, SP, Brasil

E-mail: pchieffi@usp.br

Work not supported by any sources other than from this laboratory.

Presented at the $36^{\text {th }}$ Brazilian Congress of Clinical Pathology and Laboratory Medicine, held in São Paulo, 2002.

Received on $1 / 11 / 2002$. Reviewed on $11 / 7 / 2003$. Approved on $6 / 8 / 2003$. 
(c) 2003 Faculdade de Saúde Pública da Universidade de São Paulo

Avenida Dr. Arnaldo, 715

01246-904 São Paulo SP Brazil

Tel./ Fax: +55 11 3068-0539

revsp@orq.usp.br 